\title{
Imago Therapy: A Strategy to Improve Couples Lovemaking
}

\author{
Dr. Hassan Mirza Hosseini \\ Professor assistant of the Department of Psychology and the faculty member of Qom Branch of Islamic Azad University \\ Email: mirzahoseini.hasan@yahoo.com
}

\author{
Azam Movahedi \\ Student of Ph.D. in Counselling and professor of Tehran South Branch of Payame Noor University \\ Email: leonoreh@gmail.com
}

\section{Doi:10.5901/mjss.2016.v7n4s1p242}

\begin{abstract}
The main objective of this research is the effectiveness of imago therapy (therapeutic relationship) education on the attitude of lovemaking couples. The research method was of pretest-posttest type with the control group. The statistical population includes all the couples referring to Aramesh Counseling center in 2014-2015. To perform the research, 30 couples were selected in random sampling method and placed into two groups of trial and control. The experimental intervention (imago therapy) was operated on the trial group in 9 sessions each 90 minutes and 30 times per week. To study the attitude of lovemaking, LAS questionnaire and to analyze data of inferential statistical method of multivariate covariance analysis (MANCOVA) by SPSS-23 software, data was analyzed. The research results with a meaningful level of $p<0.05$, showed that imago therapy education in group style leads to increase the attitude of lovemaking.
\end{abstract}

Keywords: Imago Therapy, attitude of lovemaking, LAS

\section{Introduction}

Marriage is one of the most important decisions that everyone will made in his/her life. The marriage has a huge impact on the lives of individuals, families and even the community. One of the psychological needs of a human is "love". The heart of the man depends on loving and family need to be loved more than anything. It should be noted that to make the marriage stable, love should always be on the way to the hearts because hearts meet each other in a point and love leads to love. In a proper relationship between husband and wife, the man is active (demanding) and the women passive; of course, being active and interest of the man to wife, has a direct relationship with the personality and behavior of wife in own desirability. Of course, I mean the desirability is a true love between husband and wife. Nevertheless, the core of this relationship is woman and friendship and love of husband to his wife depends on the quality of his relationship with the wife (Movahedi, 2015). What psychologists and counselors believe is that an effective relationship is one of the strongest tools for healthy living. Effective relationships is not a relationship that leads to personal benefit, but it is a bilateral beneficial and targeted relationship and leads to psychological recovery of both parties. One of the important aspects of marriage is of emotional issues. What is referred to as love (Darvishzadeh and Pasha, 2010).

In recent years, love is considered as a criterion for choosing a spouse. The belief is that the emotional bond between the couples with love to continue a long relationship is enough. Most people agree, given the intimate relationship for a stable life. In fact, love is an experience that follows the logic and reasoning and therefore it must reject reason. While everyone has some information about the failure of love, or it should be told that some people have experienced that romantic love is the fragile foundation of the relationship between two people, but most people still believe in romance (Golestaneh, Mohanaee, Jokar, 2015). Love at first is a state of physiological emotional arousal, but there are cognitive and behavioral components. Its cognitive aspects include intrusive thoughts, persistent preoccupation to the favorite person, idealizing him or idealizing the relationship with him and wishing to be familiar with him/her (Hatfield, 1993).

In fact, love is not necessarily an immutable and permanent situation which we find something outside of ourselves. But the issue is that the love potential is inside us and is as our willingness to love others and care for them. Long-term love does not come automatically, but requires serious effort that is not selfishness and no fear of vulnerability (Greenberg, 2013; translated by Feizi, 2014). 
Love is a complex neurological phenomenon that is based on trust, believe, fun and rewarding activities of the brain (limbic structures) (Eats and Stefano, 2005, quoted by Ghamarani and Jafar Tabatabai, 2006). Communication skills training improves the attitude to love and marital boredom reduction (Sajjad, Roshan, 2015). In imago therapy (therapeutic relationship), there is a more accurate impression of romantic relationships to individuals, and marriage is not considered as a static something between two people, but the marriage is considered as a psychological and spiritual journey that is began in the attarctiuon shade. He/she Your way out of difficult to leave behind relatives and intimate unity for all life be built (Hendrix, translation Gharachedaghi, 1383). He/she passes through a long and different way to build relatives and intimate unity for all (Hendrix, translated by Gharachedaghi, 2004). The therapeutic relationship based on mental dynamics and relationship vision is based on the treatment and changes analyze and transmission between the couple and therapist to solve transmission between couples (Hatfield, quoted by Etemasi, 2005). Imago therapy (relationship imagery) is a method in couples therapy and is a combination of the main theories of personality, behavioral science, physiology, and spiritual knowledge (Ashley, 2015). The word Imago is the Latin equivalent of an imaging picture that has been used since Plato for emotional description and the intuitive sense leads to see a special person, so that we have met him/her for years and have him/her in mind and we think we fell in love with him/her. Because such an imaging has an unconscious aspects, its power and influence on the person is more (Daniel-burke, 2015). Imago is a significant factor in the selection because it is targeted to improve the integrity of the individual and by its revival. The communicative imaging pioneers include not only Freud and system theories but the social Freudists, such as Harry Stack Sullivan's interpersonal theory, me and you philosophy of Martin, social learning theories from the western mysterious rituals and knowledge of quantum physics (Brown \& Reiohold, 1999).

Relationship imaging is a paradigm to increase communication between couples, modify growth consolidation, heal the wounds of childhood, rise differentiation from the other side and revival of contacts between them. They added that Imago is a communicative model of couples therapy that applies behavioral, emotional and cognitive interventions to facilitate understanding and the inner changes of two people (couples). The objective of the relationship imaging is to revive the spiritual and emotional contact between couples as well as individuals, to create a new purpose for marriage (Egerton-warburton \& Cynthia, 2015). The main goal is to create a healing environment or relatives space in which each spouse is able to satisfy needs (unmet needs) and feelings related to neglecting and worthlessness of the other partner. In other words, it can be said that imago is like the final stage in the metamorphosis of a butterfly. Since every human has a subconscious image of ideal care during primary interaction in childhood, this image is the Imago (Ashley, 2015). A person who enters a love relationship with such a person, this ideal image is excited by unconscious wishes to complete the unmet needs of childhood. As a result, a person selects the person with the same unmet childhood experiences and needs and we tend to have positive and negative characteristics similar to the ones that we had in childhood. In this way, the therapist performs abstract and special techniques that are effective and helps couples to strengthen themselves. Homework is reviewed and practical sessions will be controlled during the weeks of treatment. Imago therapy is a belief system on committed shared relationship ((Hndrix, 2006). In other words, couples dialogue is the main and the only intervention by the therapist through the educational and psychological process and treatment program that can facilitate. The first step is to reflect, listen actively by which the couple are sure through the process of reflection and they heard the exact content of the dialogue of the other side. Secondly, validation that is created between two gaps of a bridge.

Considering the speaker and the listener skills in this relationship of spousal support can be useful. In each of these programs the couples have opportunities to practice new skills and receive feedback from education. In this method, taking into account the assignments between sessions and meetings, they are forced to practice their skills in relation to themselves. This educational program helps participants to convey their messages more explicit and achieve to a greater understanding (Egerton-warburton, Cynthia, 2015). Babar argue that accreditation as a way in which is not necessity to verify, but is known as "comprehensibility" truth.

In other words, it depends on the framework and inner context of the person. Adding emotional and empathy parts in the process is according to the research done by Rogers, Kohat and Hoffman. Imago therapy is a distinction between the two levels of empathy, cognitive empathy and predictor empathy, and in the third round it help couples to give structure to their dialogue; in other words, the couple dialogue level is based on an artistic level that is bleak and three previous steps combined and a new flow in which interactions are not symbiotic and can say that the couple dialogue is the basic structure for intervention in imago therapy (Berger \& Hannah, 1999).

In general, it can be said that the main tool for couples is dialogue. In this method, the couples learn to listen to each other and exhibit themselves in a three-part process that is mentioned above. On the progress of the treatment process, there are five kinds of dialogue that are used as follows:

1. Re-imaging of the wife: this way is carried out by dialogue about wife and problems in childhood occurred to him/her by practice. 
2. The request to change the behavior: this type of dialogue is to help communication between couples to satisfy their needs without reproach and threat.

3. Controlling: As we know, the anger is natural and normal response to failure, but may be expressed in destructive ways that this kind of dialogue considers the anger control in the couple's interactions.

4. Love again: pleasure in imago therapy means sinking in the river of life full joy, of course, for us, it is the wellbeing and life.

5. Again insight: Couples imagine actively their characteristics and behaviors in a dreamy relationships. They are urged to define their special goals more clearly, thus it would improve relationship and achieve the integrity of the individual.

In imago therapy, the therapist manages the treatment stage and he/she does not believe giving idea and advice, but he/she leads the couples to the process of dialogue so that the couples are powerful and each is a therapist for another (Brown \& Reiohold, 1999). In other words, imago therapy, the traditional role of the therapist is facilitator. In this approach, there are interpretation, experience and other interactions and exchanges when anxiety arousal. As a result, the therapist makes powerful the couples with their work that include: obtaining information that leads to deepening knowledge of each other and grow empathy, understanding, and internalize the process of improvement and their plans so that they can continue working with each other. In some cases, at the beginning of the work one of the couples does not want to enter the treatment, it is because he/she feels he/she is here to be known as guilty.

When only one of the couples enters treatment, only after a few weeks the couple who was not an applicant to treatment, when he/she sees changes in the spouse, he/she will join to the process of treatment (Egerton-warburton \& Cynthia, 2015).

Jameie (2013) conducted a research titled the study the effectiveness of imago therapy on the quality of marital relationships and empathy among the couples referring to counseling centers and showed that the imago therapy education is effective in improvement of total score of quality of marital relationship and its components (satisfaction in relationship or marital satisfaction), the time that the couple spend together, the possibility of separation and difference frequency, but conflict management and as well as imago therapy techniques education increases empathy in the subjects of experimental group.

The research carried out by Salouri Mahmoudabadi (2014) showed that couple therapy of relationship image is as an effective way to increase marital communication, intimacy, mental health and there is a significant increase between imago therapy and mental health.

Khoshsirat (2014) conducted a research on the effects of short-term couple therapy with imago therapy method on the marital compatibility and satisfaction in the first 2 years of life and found that the use of imago therapy increases significantly the marital compatibility and satisfaction. Imago therapy understand deeply their inner by improving marital compatibility and satisfaction. Sadr Jahani (2010) in his data analysis found that relationship imagery education leads to increase marital intimacy.

Hafezi and Jameinejad (2009) in his research found that there is a multiple relationship between love, positive affection, negative affection and attachment styles with marital satisfaction. Veisi (2009) in his research showed that communication techniques education help increase women's marital satisfaction.

Bayat (2007) in his research titled the study of the effect of imago therapy on the attitude of love of girls students of Isfahan University and found that imago therapy education has a significant effect on love attitudes of the girls.

Ghaemi (2009) in his research found that imago therapy and treatment schemas affect love addiction and inconsistent schemas in girls and there is a meaningful relationship between love addiction and inconsistent schemas in girls.

Etemadi (2005) did a research titled the study of effect of the couple therapy by imago therapy method on increasing marital intimacy. The results showed that imago therapy education increased emotional, intellectual, physical and sexual intimacy in couples.

Hatfield et al (2007) studied the relationship between schemas of love and marriage priorities and in their results they found that people in the first stage prefer those who have schemas of safe or ideal love and secondly select those who are like them.

Hendrick et al (1998) found that women showed more pragmatic ways of love compared with men and they were more likely to maintain their relationships. Also they found that certain experiences of love meet couple's performance, especially in the formation and progress of relationships. Imago therapy uses marital therapy and education to help couples to better understand imago therapy effect on the marital relationship.

As we know, early intervention is done by the therapist to restore the marital relationship. It can be said that no study has been done on imago therapy by randomized control but there is some support for pre-treatment and post- 
treatment comparisons that has not used control groups (Etemad, 2005).

Love and imago therapy share the past. In other words, the past of people makes their love partners and their relationship. So healing the past relationships may have an impact on the attitude of couples lovemaking (Levine, 2000). As we know, loving another person may be challenged and should be found a basic way.

Today, there are ways to enhance the attitude of lovemaking and imago therapy is one of them. However due to the fact that one of the ways to increase intimacy and lovemaking between couples is education and education in the field of infrastructure skills of relationship is one of the effective ways, therefore the main purpose of this research is to answer the question whether education based on imago therapy affect the attitude of lovemaking?

\section{The Research Methodology}

The present research method was of pretest-posttest type with the control group. The statistical population includes all the couples referring to Aramesh Counseling center in 2014-2015. To perform the research, 30 couples were selected in random sampling method.

\subsection{Measurement Tool}

\subsubsection{The Questionnaire of Lovemaking}

To measure the dependent variable, lovemaking LAS questionnaires were used. This scale is made by Hendrik (1998) and is translated by Dr. Mortazavi in 2002. Its content validity was evaluated and verified by five experts. The reliability of love view scale was determined 0.83 on 30 people of preliminary sample as per Cronbach's alpha. The questionnaire has 24 questions and answers to females is in Likert method and as 5 -item of completely agreed $=4$ to completely disagreed. In this scale, the score of 96 indicates realistic sign of love and whatever the score is reduced sign of love is romantic. In the present research to determine the reliability of the attitude of lovemaking view questionnaire, the Cronbach's alpha method was used that for the whole questionnaire with Cronbach's alpha 0.83 indicates acceptable reliability of the questionnaire.

\subsection{The Research Performance Method}

First the couples referring to the counseling center were pre-tested. Then 30 couples were randomly selected and divided into two experimental and control group. After performance of 90 educational sessions (each 90 minutes) on the experimental group, the two groups were post-tested. Therapy sessions was as follows: the first session: communication and preparation, the second session: Future relations planning, the third session: increasing self-awareness, the fourth session: knowing wife, fifth session: understanding the needs and damages of each other, sixth session: blocking the exit ways, seventh session: re-making romantic relationship, eighth session: learning new behaviors and making committed conscious relationship, ninth session: integration. To analyze collected data, univariate covariance analysis was used. The significance level for all hypotheses was considered $a=0.05$.

\section{Findings}

The descriptive results of this research included mean statistics indicators and standard deviation of the scores of attitude of subjects love in Table 1 is presented.

Table 1: The mean and standard deviation of the score of the attitude of love of the couples in the experimental and control groups in pre-test and post-test

\begin{tabular}{cccccccc}
\hline Total & Maximum & Minimum & Standard Deviation & Average & Statistical Index-Group & Stage & Variable \\
\hline 15 & 110 & 65 & 11.78 & 87.30 & Test & Pre Test & \\
15 & 96 & 62 & 11.45 & 79.80 & Control & & Attitude of Lovemaking \\
15 & 128 & 87 & 13.35 & 106.85 & Test & Post Test & \\
15 & 96 & 60 & 11.80 & 77.65 & Control & & \\
\hline
\end{tabular}

As shown in Table 1, in the pre-test, the mean and standard deviation of each of the following groups are as follows: the 
experimental group 87.30 and 11.78 , the control group 79.80 and 11.45 , in the post-test the mean and standard deviation, the experimental group 106.85 and 13.35 , the control group 77.65 and 11.80 .

The findings related to the research hypothesis

At first, to comply with the default of equality of variances, the research variables have been used from Levene test and the results are shown in Table 2.

Table 2: The results of Levene test on the default of equality of variances of the scores of the love attitude in two groups

\begin{tabular}{cccccc}
\hline Third Freedom degree & Second Freedom degree & First Freedom degree & $F$ & Variable & Stage \\
\hline 0.795 & 28 & 1 & 0.069 & The attitude of lovemaking & Pre-test \\
\hline
\end{tabular}

As shown in Table 2, the null hypothesis for the equality of variances, the score of two groups in the dependent variable of the research (the attitude of lovemaking) is confirmed, i.e. the default of the equality of variances, the scores in both experimental and control groups are confirmed.

Hypothesis of the research: Imago therapy (therapeutic relationship) has an effect on the attitude of lovemaking of the couples. Table 3 shows the results of the research hypothesis.

Table 3: The results of single-variable covariance analysis on the post-test of the mean score of the attitude of lovemaking of the couples of the experimental and control groups

\begin{tabular}{|c|c|c|c|c|c|c|c|c|}
\hline $\begin{array}{c}\text { Statistical } \\
\text { power }\end{array}$ & $\begin{array}{l}\text { Eta } \\
\text { Chi }\end{array}$ & $\begin{array}{c}\text { P significance } \\
\text { level }\end{array}$ & $\mathrm{F}$ & $\begin{array}{c}\text { Mean } \\
\text { squares }\end{array}$ & $\begin{array}{l}\text { Degree of } \\
\text { freedom }\end{array}$ & $\begin{array}{c}\text { Total } \\
\text { squares }\end{array}$ & $\begin{array}{c}\text { Changes } \\
\text { source }\end{array}$ & Variable \\
\hline 0.551 & 0.18 & 0.044 & 4.89 & 654.88 & 1 & 654.88 & Pre-test & \\
\hline 0.986 & 0.58 & 0.001 & 17.08 & $\begin{array}{c}2198.86 \\
138.70\end{array}$ & $\begin{array}{c}1 \\
20\end{array}$ & $\begin{array}{l}2198.86 \\
2835.08\end{array}$ & $\begin{array}{l}\text { Group } \\
\text { Error }\end{array}$ & $\begin{array}{l}\text { The attitude of } \\
\text { lovemaking }\end{array}$ \\
\hline
\end{tabular}

As shown in Table 3, there is a significant difference by controlling pre-test between the couples of experimental and control groups in terms of the attitude of lovemaking $(F=17.08$ and $p<0.001)$, so the hypothesis is confirmed. In other words, imago therapy (therapeutic relationship) leads to improve the attitude of lovemaking of the couples in the experimental group in post-test than the mean of the couples of control group, according to the mean of post-test attitude of the couples in the experimental group. The effect or difference is equal to 0.58 , i.e. $58 \%$ of individual differences in the scores of post-test of the attitude of lovemaking related to the effect of imago therapy (therapeutic relationship). Statistical power is equal to 0.986 .

\section{Discussion and Conclusion}

In explaining the findings, it can be said that the significance of the hypotheses shows that the imago therapy in the people's attitude to love towards the realistic love attitude has been effective. The above results are in live with the findings of the research done by Hameie (2013), Salouri Mahmoudabadi (2014), Khoshsirat (2014), Nezakati (2014), Bayat (2007), Etemadi (2005), Sadr Jahani (2010), Veisi (2009), Dijklrav Baldz (2008), Hatfield and colleagues (2007), Weigel (2006.

As we know, the love is formed from an inner subconscious force and our childhood experiences and our romantic choice is influenced by romantic childhood patterns. Imago therapy look at love with a new structure and considers it as a marginal issue. In this way, love and its process have been studied more than any other couple therapy and they go in search of their love and they help their understanding of the way of love, aspirations and expectations and rebuilding the concept of love. In its structure, imago therapy considers incomplete and denied aspects of people's character and reconstructs an imaginary picture of people by providing a real picture. Imago therapy helps people who adjust their expectations from their wife and consider denied and hiding aspects of their characters. The relationship imagery is a theory and treatment method of committed partnership with emphasizing on marital relationship. The underlying assumption of marital selection approach is based on the romantic allure and unconsciously. After the choice of spouse, the outcome of the competition-unconscious between a subjective image of parent or care of a child is created called Imago. Imago is a significant factor in the selection. Because the unconscious of people is guided with the aim of improving the integrity of the person, by reviving the relationship, both personal and interpersonal which was broken 
down in childhood. Therefore, at any level, the romantic love is the predicted result to the people's satisfaction. Therefore, it is recommended to marriage and family counselors suggest to improve the attitude of lovemaking by using treatment method of imago therapy. On the other hand, it is added as one of psycho-educational interventions on other counseling interventions. Also having business license must be as one of the marriage contract terms and conditions to people are bound to acquire these skills before marriage problems. Later researchers are able to educate these skills to the persons who are getting married and examine the positive and negative results of their marriage. Also the surveyed men and women are matched entirely based on variables such as the type of problem, duration of marriage and types of childhood problems to investigate the effects of the relationship imagery on multiple other problems. It is recommended that if possible, the couples are matched in terms of conflicts to study the effectiveness of this approach in varying degrees. This research needs the longitudinal studies.

\section{References}

Etemadi, Ozra (2005). The study and comparison of the effectiveness of psycho-educational approach based on cognitive-behavioral and therapeutic relationship on the couples intimacy. The thesis for Ph.D. in the field of Counseling, Tarbiat Moallem University of Tehran.

Bayat, Maryam (2007). The study of the effectiveness of imago therapy on the attitudes of lovemaking of the girl students of Isfahan University, unpublished article, Isfahan University.

Hafezi, Fariba, and Jameienejad, Farahnaz (2009). The relationship between love, positive affection, negative affection and attachment styles with marital satisfaction in the employees of National Iranian Drilling Company of Khuzestan. New findings on psychology, $4^{\text {th }}$ year, No. 10 , pages $41-52$

Jameie, Masoumeh (2013). The study of the effectiveness of imago therapy on the quality of marriage and empathy among the couples referring to the counseling center, senior expert of family counseling, Shahid Chamran University of Ahvaz.

Khoshsirat, Mandana (2014). The effect of short-term couples therapy by imago therapy method on the consistency in marital satisfaction in the first 2 years of martial relationship. The senior expert of psychology, Welfare Science and Rehabilitation University.

Darvishzadeh, Sara and Pasha, Gholamreza (2010). The study of the effectiveness the Education before marriage on love story of the students., new findings on psychology, $5^{\text {th }}$ year, No. 14, pages 7-23

Sajjadi, Seyedeh Faezeh, Roshan Rasoul. The effectiveness of communicative skills on improvement of attitude of love and reducing marital boredom. The scientific and research quarterly of counseling research. 2015, 14 (53): 91-111

Salouri Mahmoudabadi, Zinat (2014). The effectiveness of relationship imagery on compatibility, intimacy and mental health of married women, the senior expert of family counseling, the faculty of educational science and psychology

Sadr Jahani, S., Etemadi, A., Saadipour (Biabangard), A., Arian, S. (2010). The effectiveness of imago therapy techniques education (relationship imagery), marital intimacy of addicts and their spouse, research on addiction, 3, 25-44

Ghaemi, Zahra (2009). The study of combined approach effect (imago therapy and treatment schema) on love addiction and schema of girls in Isfahan, the senior expert of family counseling, the faculty of educational science and psychology, Isfahan

Ghamarani, Amir and Jafar Tabatabaei, Samaneh Sadat (2006). The study of Iranian couples romantic relationship and their relationship with marital satisfaction. The quarterly of counseling news and research, the $5^{\text {th }}$ volume, No. 17 , summer.

Grinberg, Malani (2013). Some scientific facts about love. Translated by Ali Feizi (2014). Tehran: the center of psychology service and life counseling

Movahedi, Azam. (2015). The key points on a successful marital relationship. Qom: Khakian publication

Nezakati, Rezazadeh, N. (2014). The effectiveness of couples therapy based on relationship imagery on marital intimacy of married women without identity

Veisi, Asadollah (2009). The effectiveness of imago therapy techniques education on martial satisfaction among the married women of the faculty of psychology of Allameh Tabatabaei University, the knowledge and research on applied psychology, Khourasgan Branch of Islamic Azad University, Isfahan, No. 42, 92-107, winter

Ashley, A. A. (2015). Discover a New Way to Love in 2015. Carole Kirly.

Berger, R., \& Hannah, M. (1999). Preventive Approaches couple therapy. Philadelphia:Taylor \& Francis Group.

Brown, R., \& Reiohold, T. (1999). Image relationship therapy. New yourk: John Wiley \& Sons.

Daniel-burke, R., Development, O. P., Guest, A. C. A., \& Hammonds-white, S. (2015). ACA Podcast series: HT062 Imago Relationship Therapy May 2015, 1-17.

Dijkra, P., \& Barelds, D. P. (2008). Do people know what They want: A similar or complementary partner? Evolutionary Psychology, 6 , $595-602$.

Golestaneh, S. M., Mohanaee, S., \& Jokar, M. (2015). The effectiveness of couple 's therapy training on increasing of psychological capital of couples, 4, 66-72.

Hatfiled, E., Singelis,T., Levine, T., Bachman, G., Muto, K., \& Choo, P. (2007). Love schemas, preferences in romantic portners, \& reactions to commitment. Interpersonal Journal,1,1-24.

Hatfiled, E. (1993). Passionate love. INR. J. Sternberg \& M. L. Barnes (Eds) the psychology of love (PP. 191 - 217). New Havern, CT: Yale University Press. 
Hendrick. C., Hendrick, S. S., \& Dicke. A. (1998). The Love Attitudes Scale: Short Form, Journal of Social and Personal Relationships, 15(2), 137- 142.

Levin, J. (2000). A prolegomena to an epidemiology of love theory, measurenment and health outcomes, Journal of Social and Clinical Psychology, 19(1), 117-136.f Social and Personal Relationships, 15(2), 137-142.

Hendrix, H. (2006). How to keep your relationship shape: An introduction to Imago.

Weigle, J. B. (2006). The Impact of Participating in an Imago Therapy Workshop on Marital Satisfaction. Unpublished doctoral dissertation. Walden University. 